\title{
BMJ Open Technology-based interventions for nursing home residents: a systematic review protocol
}

\author{
Zhaohui Su (D) , ${ }^{1}$ Kylie Meyer, ${ }^{2}$ Yue Li, ${ }^{3}$ Dean McDonnell, ${ }^{4}$ \\ Nitha Mathew Joseph (1) , Xiaoshan Li, ${ }^{6}$ Yan Du, ${ }^{2}$ Shailesh Advani, ${ }^{7}$ \\ Ali Cheshmehzangi (D) , Junaid Ahmad, ${ }^{9}$ Claudimar Pereira da Veiga, ${ }^{10}$ \\ Roger Yat-Nork Chung (D) , ${ }^{11,12}$ Jing Wang, ${ }^{13}$ Xiaoning Hao ${ }^{14}$
}

To cite: Su Z, Meyer K, Li Y, et al. Technology-based interventions for nursing home residents: a systematic review protocol. BMJ Open 2021;11:e056142. doi:10.1136/ bmjopen-2021-056142

- Prepublication history and additional supplemental material for this paper are available online. To view these files, please visit the journal online (http://dx.doi.org/10.1136/ bmjopen-2021-056142).

Received 04 August 2021 Accepted 25 October 2021
Check for updates

(C) Author(s) (or their employer(s)) 2021. Re-use permitted under CC BY-NC. No commercial re-use. See rights and permissions. Published by BMJ.

For numbered affiliations see end of article.

Correspondence to Dr Zhaohui Su; szh@utexas.edu and Xiaoning Hao;

haoxn@nhei.cn

\section{ABSTRACT}

Introduction A growing number of technology-based interventions are used to support the health and quality of life of nursing home residents. The onset of COVID-19 and recommended social distancing policies that followed led to an increased interest in technology-based solutions to provide healthcare and promote health. Yet, there are no comprehensive resources on technology-based healthcare solutions that describe their efficacy for nursing home residents. This systematic review will identify technologybased interventions designed for nursing home residents and describe the characteristics and effects of these interventions concerning the distinctive traits of nursing home residents and nursing facilities. Additionally, this paper will present practical insights into the varying intervention approaches that can assist in the delivery of broad digital health solutions for nursing home residents amid and beyond the impact of COVID-19.

Methods and analysis Databases including the PubMed, PsycINF0, CINAHL and Scopus will be used to identify articles related to technology-based interventions for nursing home residents published between 1 January 2010 to 30 September 2021. Titles, abstracts and full-text papers will be reviewed against the eligibility criteria. The Cochrane Collaboration evaluation framework will be adopted to examine the risk of bias of the included study. The Preferred Reporting Items for Systematic Reviews and Meta-Analyses procedures will be followed for the reporting process and implications for existing interventions and research evaluated by a multidisciplinary research team.

Ethics and dissemination As the study is a protocol for a systematic review, ethical approval is not required. The study findings will be disseminated via peer-reviewed publications and conference presentations.

Trial registration number CRD 42020191880.

\section{BACKGROUND}

Nursing homes have been described as a 'ground zero' throughout the COVID-19 outbreak. $^{1-4}$ While the final impact of COVID-19 on short-term and longer-term health outcomes is still unclear as the pandemic continues to unfold, ${ }^{5}$ what is clear is that nursing home residents have
Strengths and limitations of this study

- This systematic review protocol follows the Preferred Reporting Items for Systematic Review and MetaAnalysis Protocols guidelines.

- Our review will systematically evaluate the impact of technology-based interventions for nursing home residents.

- The social ecological model will be adopted to theoretically and systematically guide our review process

- The current study is limited to evidence within the scope of nursing home residents and technologybased interventions.

- Non-English databases will not be searched, which might limit the representativeness of the research findings.

suffered some of the gravest consequences of this pandemic so far. ${ }^{6}$ Contributing to over $40 \%$ of COVID-19 deaths within the USA, 100033 residents and workers in nursing homes have passed away from COVID-19 (as of 24 November 2020). ${ }^{7}$ Worse still is the fact that the nursing home residents who have succumbed to COVID-19 mostly died without the care or company of their family members. $^{8-10}$ These staggering numbers underscore the urgent need for healthcare researchers to understand factors that make nursing home residents more vulnerable to emergency events such as COVID-19 $9^{11}$ and to identify practical solutions that can address these factors in a timely fashion.

Nursing homes and nursing facilities provide long-term service and support for individuals living with chronic or disabling conditions who are unable to live at home independently. ${ }^{12-14}$ Often living with multiple morbidities, in the USA, approximately $85.1 \%$ of nursing home residents are 65 years and older, with $75.8 \%$ of these individuals 
experiencing hypertension, $58.9 \%$ living with Alzheimer's disease and $53.0 \%$ of residents living with depression. ${ }^{14}$ Three sets of factors likely contribute to the alarming COVID-19 death rates seen in nursing homes: (1) the characteristics of nursing home residents, (2) the capabilities of nursing home facilities and (3) the microlevel and macrolevel supports available to nursing home residents. ${ }^{11}$ On both microlevel and macrolevel, research indicates that nursing home residents are more susceptible to infection and fatal outcomes from COVID-19 because they are often older adults living with medical conditions that compromise the immune systems and lowers their ability to combat the virus. ${ }^{14-17}$ Additionally, they often lack specific self-care skills, such as using telemedicine tools, or they may have a physical or cognitive impairment that impedes their ability to take care of their health and well-being. ${ }^{18-22}$ The macroperspective focuses on the unique characteristics of nursing home facilities, as they are typically operating in a close and shared-living environment-conditions that are ideal for the spread of the virus. ${ }^{101723}$ Further, nursing homes often lack adequate healthcare resources or infrastructure needed to curb the impact of COVID-19. For example, numerous studies have indicated a lack of investment in training programmes for nursing home staff, in addition to high turnover rates, ${ }^{2425}$ that management teams are often ineffective $^{2627}$ and that the nursing home infrastructure is often too outdated. ${ }^{23}$ 28-30

The third set of factors that contribute to nursing home residents' vulnerability to COVID-19 centres on social support available to these adults. ${ }^{11}$ Nursing home residents often have limited access to microlevel social support, including support from formal (eg, doctors and nurses) or informal caregivers (eg, family, friends and acquaintances), ${ }^{31}$ local community ${ }^{32}$ and organisations (eg, inexperienced or inadequately trained staff). ${ }^{33}$ Furthermore, nursing home residents often have limited macrolevel social support. This is evidenced by harmful social norms (eg, age-related discrimination $)^{34-36}$ and inadequate policy support that facilitates healthy ageing and quality of life (eg, insufficient regulatory oversight to ensure quality care in nursing homes) ${ }^{437-39}$ These factors combined could result in severe health consequences in nursing home residents, such as wide viral spread. ${ }^{1}$

The above areas of inquiry resonate with the core principles of the socioecological model, ${ }^{40-43}$ which highlights the way individuals are influenced by a series of synergistic interactions between intrapersonal and interpersonal factors (eg, residents, resident families), organisational characteristics (eg, nursing homes), policy (eg, legislative response) and the social/community (eg, ageism) context and how these processes can change over time (see figure 1.) To successfully and effectively protect nursing home residents from global health crises such as COVID-19, stakeholders such as policy-makers, healthcare professionals, researchers informal caregivers and older adults themselves all need to contribute to the changemaking process (eg, research safeguards or underscores the importance of COVID-19 protective measures) ${ }^{44-49}$ While some effective changes are resource intensive, time consuming and need concerted efforts from multilevel stakeholders to achieve, there are cost-effective, efficient and accessible health solutions available to nursing home residents, such as technology-based interventions. ${ }^{50} 51$

Technology-based interventions can be considered as the use of technology (eg, digital devices such as tablets and wearable devices, communication platforms) to manage or support health promotion strategies that could offer accessible, affordable, convenient, and user-friendly health solutions to a target audience. ${ }^{52}$ Compared with

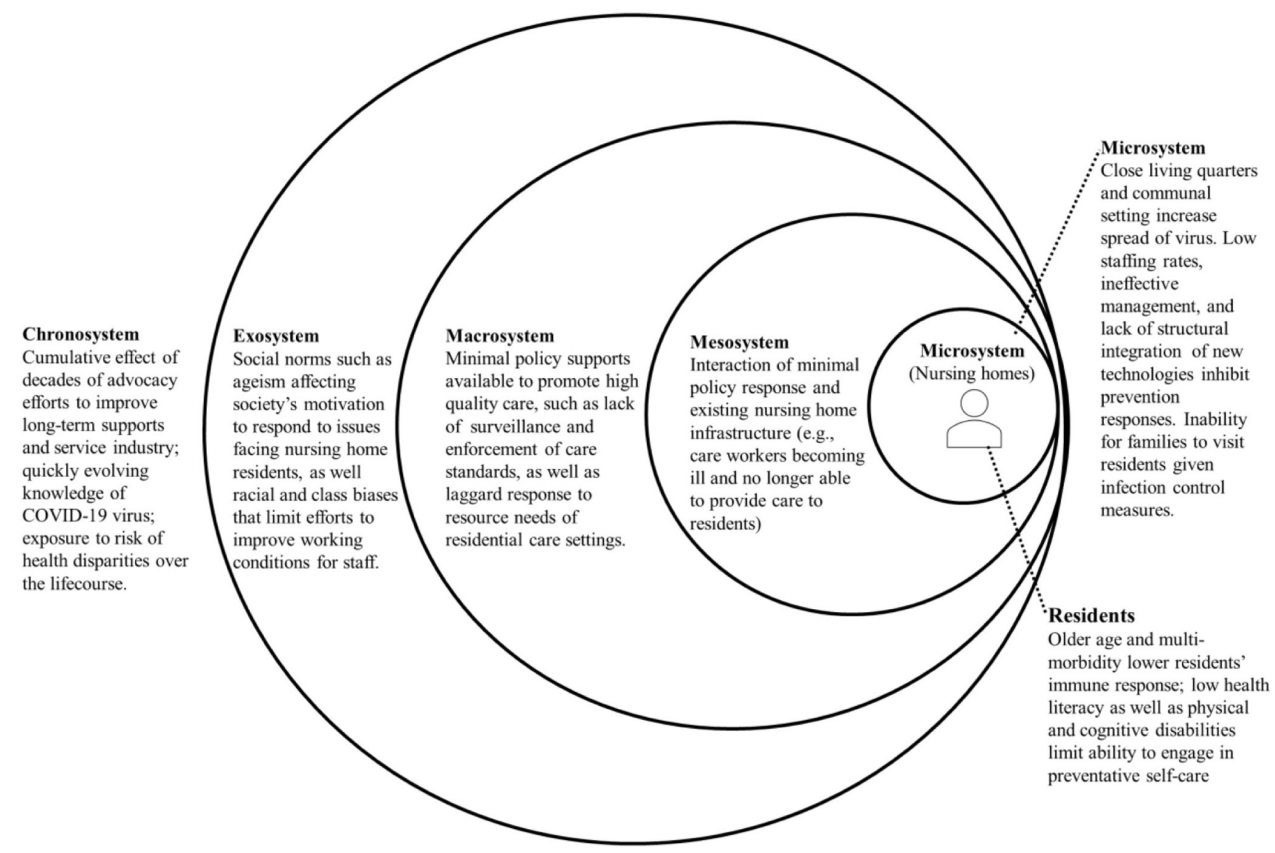

Figure 1 An ecological model of factors increasing nursing home resident vulnerability to COVID-19. 
traditional health solutions, such as face-to-face consultations, technology-based interventions have the potential to deliver healthcare more effectively and can mitigate geographic and access-related limitations that, as studies show, can play a significant role within nursing homes. ${ }^{53-59}$ The evidence further suggests that technology-based interventions can help free healthcare professionals from repetitive work and allow them to make more meaningful contributions in delivering healthcare solutions to the care recipients. ${ }^{60-62}$

Telemedicine and other technology-based solutions are particularly crucial given circumstances rendered by the COVID-19 pandemic, such as the limited ability for some healthcare providers to enter residences or for residents to visit their healthcare team for primary care visits. Limiting the exposure to infection through the use of telemedicine may assist in situations where a resident is required to attend a hospital appointment and return to a residence, thus alleviating the potential risk for a virus to spread to others. ${ }^{63}$ Further, technologies that support residents' ability to remain in contact with families and friends outside of skilled care settings may reduce the adverse effects of loneliness and social isolation that are more common among nursing home residents compared with community-dwelling older adults. ${ }^{64} 65$

While technology-based solutions have the potential to deliver health solutions to nursing home residents, ${ }^{66} 67$ there is limited awareness of the benefits and delivery options for state-of-art technology-based interventions specifically designed for nursing home residents. By factoring in the distinctive characteristics of nursing home residents and nursing home facilities, the main focus of this systematic review is to identify and evaluate technology-based interventions tailored explicitly for nursing home residents. Additionally, our study will examine the delivery mode of the interventions, such as mobile-based versus computer-based interventions and interventions that require nursing home residents' input/engagement versus those that do not require users' input/engagement (eg, sensor-based interventions) amid the COVID-19 pandemic. Overall, our research aims are:

- To identify the characteristics and effects of technology-based interventions for nursing home residents.

- To identify effective technology-based interventions for nursing home residents that can be applied in the COVID-19 context.

\section{METHODS}

The Preferred Reporting Items for Systematic Reviews and Meta-Analyses (PRISMA) procedures will be adhered to in the reporting process (please see the online supplemental file). ${ }^{68}$ This systematic review is registered with the International Prospective Register of Systematic Reviews system; these measures are to avoid unnecessary study duplication, ${ }^{69} 70$ increase research rigour, ${ }^{71} 72$ improve study comparability and replicability ${ }^{73}$ and ultimately, promote quality and transparency in research. ${ }^{74}$ The review will be carried out in line with the Cochrane Handbook. ${ }^{75}$

\section{Inclusion and exclusion criteria}

Based on the research aims, inclusion criteria were set a priori (table 1). Articles published between 1 January 2010 to 30 September 2021 will be included in the review. This time period was selected to ensure a focus on up-todate technologies, given the tendency of technologybased interventions to evolve and become out of date. The timeline will also make sure both studies conducted before and amid COVID-19 will be included in the

\section{Table 1 Study inclusion criteria}

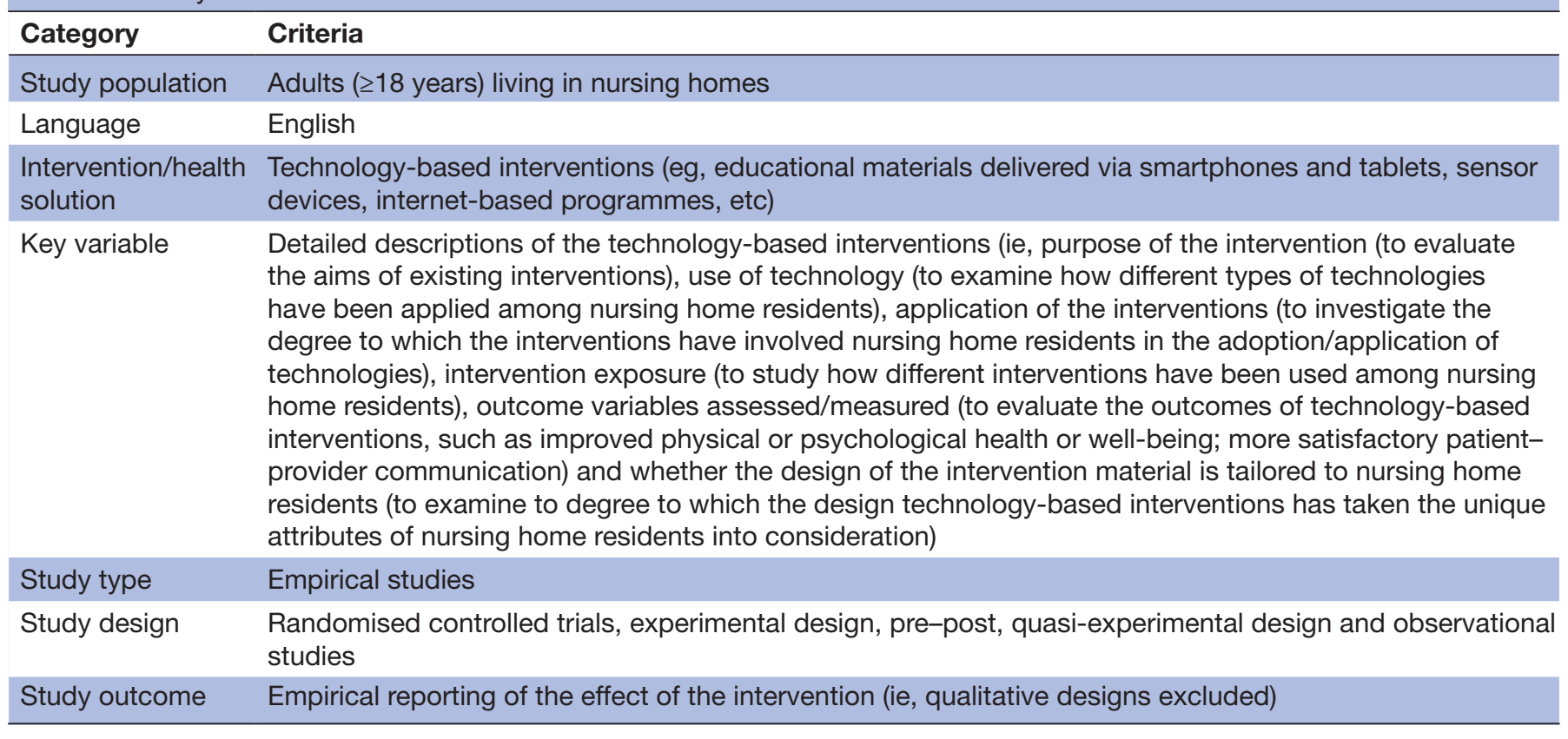


review. In this study, nursing home residents are defined as people 'having a length of stay in a nursing home for more than 90 days at any point'. ${ }^{76}$ Technology-based interventions are defined as 'the use of technology to design, develop and/or deliver health promotion contents and strategies that aim to induce or improve positive physical or psychological health outcomes' in nursing home residents. ${ }^{52}$ In other words, interventions that: (1) incorporate technology (eg, mobile applications), (2) use health promotional contents or strategies (eg, information or emotional appeals) and (3) aim to improve nursing home residents' health outcomes (eg, mental health status) will be included in the review.

It is important to note that, in this study, technologybased interventions are considered conceptually different from phenomena such as digital solutions. Compared with concepts such as digital solutions, technology-based interventions are unique as they are: (1) evidence based: one of the main objectives of this study is to investigate and identify interventions that could offer the most benefits to nursing home residents based on empirical evidence, (2) purposeful: technology-based interventions are designed, developed and/or delivered often tailored to the unique attributes of the target audience (eg, nursing home residents) and (3) broader in scale and scope: technology-based interventions include interventions that are developed based on non-digital technologies (those that are based on systems that generate and process binary data such as 0 and 1 ), such as landline telephones and audiotapes, which adopt analogue technology (stores and interprets information in line with the devices physical properties). ${ }^{77}$

Overall, articles will be excluded if (1) the study sample did not include a majority of nursing home residents (ie, nursing home residents $\leq 50 \%$ of the total research population), (2) the study did not focus on technologybased interventions (eg, conventional interventions such as face-to-face therapies), (3) study did not provide detailed information on the characteristics and effects of technology-based interventions (eg, little or no information on the design or outcomes of the interventions), (4) the study did not report original and empirical findings on intervention outcomes (eg, research protocols and systematic review studies) and (5) the study's main research method was not randomised controlled trials, experimental design, pre-post, quasi-experimental design or observational studies.

\section{Search strategy}

Databases including PubMed, PsycINFO, CINAHL and Scopus will be searched for eligible articles. We will also search ProQuest Dissertations to examine grey literature sources. A search strategy was developed in consultation with a librarian experienced in systematic review methods. Search terms used to locate articles will centre on three concepts: nursing home residents, technologybased interventions and randomised controlled trials. An example PubMed search string is illustrated in table 2. Similar search terms will be adopted that are in accordance with: (1) the scale and scope of the databases and (2) insights and evidence accumulated in the review process.

\section{Study selection}

Following the search, all citations will be collated and uploaded to Mendeley and duplicate studies will be removed. Titles and then abstracts will be screened by two principal reviewers independently. The same screening procedure will be adopted in the full-text article review process on selected article abstracts. Reasons for exclusion

\section{Table 2 Example PubMed search string}

\begin{tabular}{|c|c|}
\hline Concept & Search string \\
\hline Nursing homes & 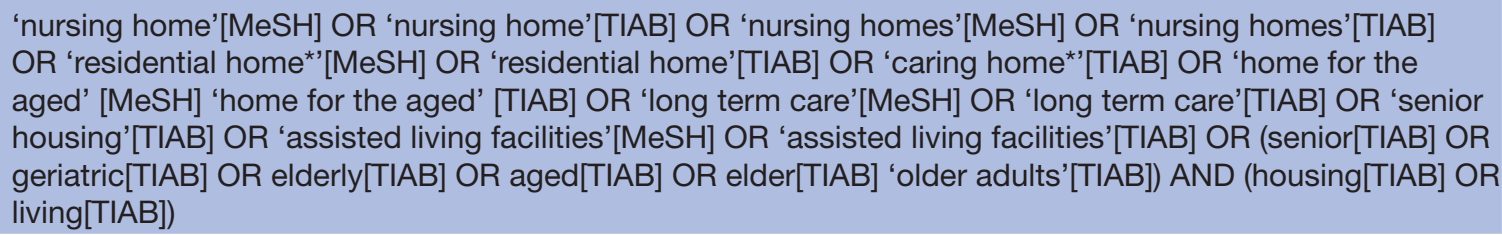 \\
\hline $\begin{array}{l}\text { Randomised } \\
\text { controlled trials }\end{array}$ & $\begin{array}{l}\text { randomized controlled trial[PT] OR randomized controlled trials as topic[MH] OR random allocation [MH] } \\
\text { OR double-blind method[MH] OR single-blind method[MH] OR random[tw] OR 'Placebos'[MeSH] OR } \\
\text { placebo[TIAB] OR ((singl*[tw] OR doubl*[tw] OR trebl*[TW] OR tripl*[TW]) AND (mask*[TW] OR blind*[TW] } \\
\text { OR dumm*[TW])) }\end{array}$ \\
\hline
\end{tabular}




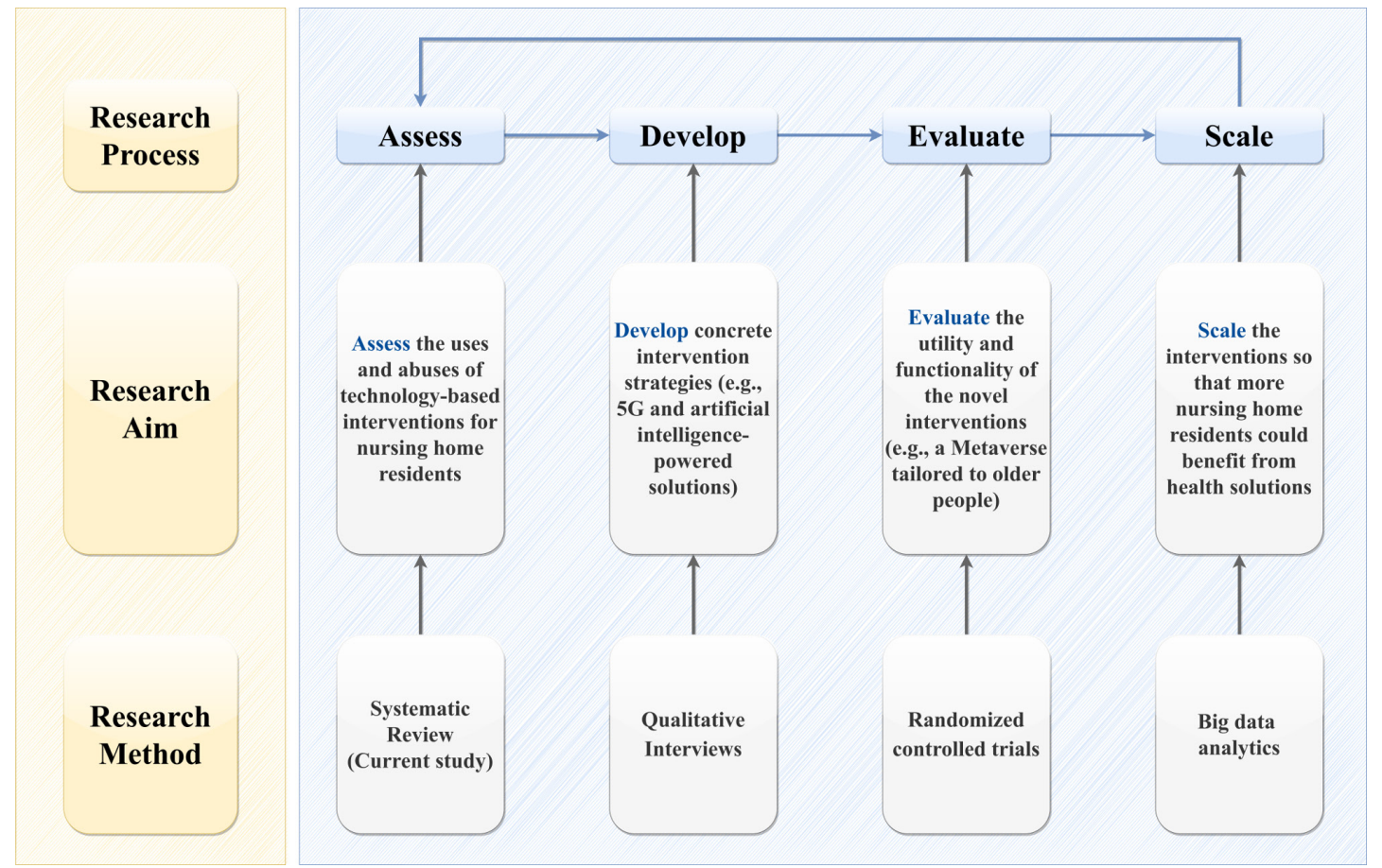

Figure 2 A schematic representation of the overarching research plan

will be recorded and detailed in the PRISMA flowchart. Discrepancies between reviewers will be resolved via group discussions using videoconferencing and email correspondence to reach a consensus.

\section{Study quality assessment}

The Cochrane Collaboration evaluation framework will be adopted to examine the risk of bias of the included study. ${ }^{78}$ The framework has seven domains: random sequence generation, allocation concealment, blinding of participants and personnel, blinding of outcome assessment, incomplete outcome data, selective reporting and any other source of bias. The risk of bias will be evaluated independently by two reviewers (ZS and XL), who will qualitatively evaluate the risk of bias and provide a score (high, medium, low). Any discrepancy regarding the risk of bias will be resolved by consensus via group discussions. Most, if not all, members of the team will be involved in the discrepancy review process, wherein, if agreement cannot be reached, outside counsel will be invited to further shed light on the issue.

\section{Data extraction and synthesis}

Data on study design, sample characteristics (ie, sample size and sample details), intervention characteristics (ie, technology type, intervention application, intervention exposure and intervention materials), outcome variables assessed and research findings will be extracted by two main reviewers (ZS and XL). Findings from the included studies will be narratively synthesised to examine the characteristics and effects of the interventions. Gaining a more structured understanding of the interventions, the multidisciplinary study team will organise insights on intervention application and outcomes in tandem with the distinctive traits of nursing home residents and the overall nursing home environment. Due to the heterogeneity found within the articles identified during a preliminary review of search results, meta-analyses are not considered.

\section{Ethics and dissemination}

As the study is a protocol for a systematic review, ethical approval is not required. Ethical research practices, such as the guideline proposed by the United States National Institutes of Health, ${ }^{79}$ will be observed and abided by throughout the research continuum. The study findings will be disseminated via peer-reviewed publications and conference presentations.

\section{Patient and public involvement}

None.

\section{DISCUSSION}

There is a growing body of technology-based interventions designed to support the health and quality of life of nursing home residents. ${ }^{53-59}$ The onset of COVID-19 and recommended social distancing policy led to an increased interest in reliance on technology-based solutions. ${ }^{80-82}$ However, research has yet to provide comparative insight into the recent state of development of these interventions and how current evidence can be applied to the context of COVID-19. The use of the socioecological model, combined with multidisciplinary expertise, provides a framework to present practical insights on how these interventions can be used to deliver health solutions to nursing home residents amid and beyond the impact of COVID-19. 
This research fills a critical gap in the literature by consolidating, in one place, the evidence for technologybased interventions empirically tested with nursing home populations. As the older adult population grows, there is an urgent need to identify effective technology-based interventions that can address the distinctive characteristics and preferences of nursing home residents. ${ }^{83-85}$ Improving person-centred care and the delivery of effective care solutions to nursing home residents, especially as the pandemic continues, is of critical importance. A comprehensive understanding of how available technology-based health solutions facilitate healthcare for nursing home residents can help shed light on approaches that are available to these residents to fend off the negative health consequences amid and beyond the influence of COVID-19. While the COVID-19 pandemic has revealed troubling vulnerabilities in the long-term care system across the globe, it also shows how telemedicine can support nursing home residents and their families. Technology can also assist clinicians in connecting with patients when in-person medical visits are difficult or dangerous (eg, in rural settings, following natural disasters) ${ }^{86}$ Overall, telemedicine and other technology-based interventions have the potential to provide a comprehensive range of benefits ${ }^{52}$ that should be sufficiently, if not fully, explored particularly in times of crises and catastrophes. ${ }^{87}$ In addition to addressing imminent and relevant social emergencies, s our overarching research (figure 2) could also inform policymaking on the use and application of technology-based interventions across nursing homes amid the pandemic and beyond. As the "silver tsunami" continues to gain momentum, it is about time for government and health officials to ready a "care tsunami" powered by advanced technologies and an avant-garde solution-focused mindset to improve the health and wellbeing of older people, especially nursing home residents. To live is but to grow old. How well societies take care of their older citizens, in essence, reflects how well humanity can be protected from the daily wear and tear of the forever grind. Following the lead of prior research, we hope this project could create a better present for nursing home residents and a more promising future for ourselves and beyond.

\footnotetext{
Author affiliations

${ }^{1}$ School of Nursing, Center on Smart and Connected Health Technologies, Mays Cancer Center, University of Texas Health Science Center at San Antonio, San Antonio, Texas, USA

${ }^{2}$ School of Nursing, University of Texas Health Science Center at San Antonio, San Antonio, Texas, USA

${ }^{3}$ Health Services Research \& Policy (HSRP) PhD \& MS Programs; Director of Research, Division of Health Policy and Outcomes Research (HPOR); Department of Public Health Sciences, University of Rochester School of Medicine and Dentistry, Rochester, New York, USA

${ }^{4}$ Department of Humanities, Institute of Technology Carlow, Carlow, Ireland ${ }^{5}$ Department of Under Graduate Studies, Cizik School of Nursing, The University of Texas Health Science Center, Houston, Texas, USA

${ }^{6}$ Program of Public Relations and Advertising, Beijing Normal University-Hong Kong Baptist University United International College, Zhuhai, Guangdong, China

${ }^{7}$ Terasaki Institute of Biomedical Innovation, Los Angeles, California, USA
}

${ }^{8}$ Architecture and Urban Design, Faculty of Science and Engineering, University of Nottingham Ningbo China, Ningbo, Zhejiang, China

${ }^{9}$ Department of Public Health, Peshawar Medical College, Peshawar, Pakistan

${ }^{10}$ School of Management-PPGOLD, Federal University of Parana—UFPR, Paraná, Brazil

${ }^{11}$ School of Public Health \& Primary Care, Faculty of Medicine (RY-NC) and Institute of Health Equity (RY-NC), The Chinese University of Hong Kong, Hong Kong, Hong Kong

${ }^{12}$ Department of Social Sciences, Faculty of Liberal Arts and Social Sciences, The Education University of Hong Kong, Hong Kong, Hong Kong

${ }^{13}$ College of Nursing, Florida State University, Tallahassee, Florida, USA

${ }^{14}$ Director of Division, Division of Health Security Research, China National Health

Development Research Center, National Health Commission, Beijing, China

Acknowledgements The authors wish to express their gratitude to Emme Lopez, the academic librarian, who helped with finalising the search strategy. Gratitude also goes to the editors and reviewers for their constructive input.

Contributors ZS developed the research idea and wrote and manuscript. $\mathrm{KM}, \mathrm{YL}$, DMD, NMJ, XL, YD, SA, AC, JA, CPdV, RY-NC, JW, and XH reviewed and revised the manuscript.

Funding This research was funded by Natural Science Foundation of China (71774034); National Key Research and Development Program of China (grant numbers: 2018YFE0197900); The Joint Pilot Project between the Ministry of Industry and Information Technology and the National Health Commission of the People's Republic of China: The Development, Standardization, and Application of 5G-Powered and Cloud-Based Virtual Critical Care and Management; The United Nations Development Program (UNDP) South- South Cooperation: Learning from China's Experience to improve the Ability of Response to COVID-19 in Asia and the Pacific Region.

Competing interests None declared.

Patient consent for publication Not applicable.

Provenance and peer review Not commissioned; externally peer reviewed.

Supplemental material This content has been supplied by the author(s). It has not been vetted by BMJ Publishing Group Limited (BMJ) and may not have been peer-reviewed. Any opinions or recommendations discussed are solely those of the author(s) and are not endorsed by BMJ. BMJ disclaims all liability and responsibility arising from any reliance placed on the content. Where the content includes any translated material, BMJ does not warrant the accuracy and reliability of the translations (including but not limited to local regulations, clinical guidelines, terminology, drug names and drug dosages), and is not responsible for any error and/or omissions arising from translation and adaptation or otherwise.

Open access This is an open access article distributed in accordance with the Creative Commons Attribution Non Commercial (CC BY-NC 4.0) license, which permits others to distribute, remix, adapt, build upon this work non-commercially, and license their derivative works on different terms, provided the original work is properly cited, appropriate credit is given, any changes made indicated, and the use is non-commercial. See: http://creativecommons.org/licenses/by-nc/4.0/.

\section{ORCID iDs}

Zhaohui Su http://orcid.org/0000-0003-2005-9504

Nitha Mathew Joseph http://orcid.org/0000-0002-5040-9299

Ali Cheshmehzangi http://orcid.org/0000-0003-2657-4865

Roger Yat-Nork Chung http://orcid.org/0000-0003-4407-8208

\section{REFERENCES}

1 Barnett ML, Grabowski DC. Nursing homes are ground zero for COVID-19 pandemic. JAMA Health Forum 2020;1:e200369.

2 Pillemer K, Subramanian L, Hupert N. The importance of long-term care populations in models of COVID-19. JAMA 2020;324:25.

3 Benson JJ, Oliver DP, Washington KT, et al. Online social support groups for informal caregivers of hospice patients with cancer. Eur J Oncol Nurs 2020;44:101698.

4 Li Y, Temkin-Greener H, Shan G, et al. COVID-19 infections and deaths among Connecticut nursing home residents: facility correlates. J Am Geriatr Soc 2020;68:1899-906.

5 Cutler D. How will COVID-19 affect the health care economy? JAMA 2020;323:2237-419.

6 Fallon Aet al. COVID-19 in nursing homes. QJM 2020:hcaa136. 
7 Kaiser Family Foundation. State data and policy actions to address coronavirus. Kaiser Family Foundation, 2020.

8 Davidson PM, Szanton SL. Nursing homes and COVID-19: we can and should do better. J Clin Nurs 2020;29:2758-9.

9 Comas-Herrera A. Mortality associated with COVID-19 outbreaks in care homes: early International evidence, 2020. Available: https:// Itccovid.org/wp-content/uploads/2020/10/Mortality-associated-withCOVID-among-people-living-in-care-homes-14-October-2020-4.pdf [Accessed 14 Oct 2020].

10 McMichael TM, Currie DW, Clark S, et al. Epidemiology of Covid-19 in a long-term care facility in King County, Washington. N Engl J Med Overseas Ed 2020;382:2005-11.

11 Su Z, McDonnell D, Li Y. Why is COVID-19 more deadly to nursing home residents? QJM 2021;114:543-7.

12 Backman A, Sjögren K, Lindkvist M, et al. Characteristics of highly rated leadership in nursing homes using item response theory. $J \mathrm{Adv}$ Nurs 2017;73:2903-13.

13 National Institute for Aging. Residential facilities, assisted living, and nursing homes, 2017. Available: https://www.nia.nih.gov/health/ residential-facilities-assisted-living-and-nursing-homes [Accessed 14 Jun 2020].

14 U.S. Department of Health And Human Services. Long-term care providers and services users in the United States, 2015-2016, in Vital and Health Statistics. Centers for Disease Control and Prevention, 2019.

15 Applegate WB, Ouslander JG. COVID-19 presents high risk to older persons. J Am Geriatr Soc 2020;68:681

16 Centers for Disease Control and Prevention. Coronavirus disease 2019 (COVID-19): older adults, 2020. Available: https://www.cdc. gov/coronavirus/2019-ncov/need-extra-precautions/older-adults. html

17 Etard J-F, Vanhems P, Atlani-Duault L, et al. Potential lethal outbreak of coronavirus disease (COVID-19) among the elderly in retirement homes and long-term facilities, France, March 2020. Eurosurveillance 2020;25:2000448.

18 Scott Kruse C, Karem P, Shifflett K, et al. Evaluating barriers to adopting telemedicine worldwide: a systematic review. J Telemed Telecare 2018;24:4-12.

19 Nouri Set al. Addressing equity in telemedicine for chronic disease management during the Covid-19 pandemic. NEJM Catalyst Innovations in Care Delivery 2020;1.

20 Berkowsky RW, Czaja SJ. Challenges associated with online health information seeking among older adults. In: Pak R, McLaughlin AC, eds. Aging, technology and health. San Diego: Academic Press, 2018: 31-48.

21 Piper AM, Brewer R, Cornejo R. Technology learning and use among older adults with late-life vision impairments. Univers Access Inf Soc 2017;16:699-711.

22 Cutilli CC, Simko LC, Colbert AM, et al. Health literacy, health disparities, and sources of health information in U.S. older adults. Orthop Nurs 2018;37:54-65.

23 Benson NM, Öngür D, Hsu J. COVID-19 testing and patients in mental health facilities. Lancet Psychiatry 2020;7:476-7.

24 Fosse A, Zuidema S, Boersma F, et al. Nursing home physicians' assessments of barriers and strategies for end-of-life care in Norway and the Netherlands. J Am Med Dir Assoc 2017;18:713-8.

25 Quigley DD, Dick A, Agarwal M, et al. COVID-19 preparedness in nursing homes in the midst of the pandemic. J Am Geriatr Soc 2020;68:1164-6.

26 Glette MK, Røise O, Kringeland T, et al. Nursing home leaders' and nurses' experiences of resources, staffing and competence levels and the relation to hospital readmissions - a case study. BMC Health Serv Res 2018;18:955.

27 Vaughn VM, Saint S, Krein SL, et al. Characteristics of healthcare organisations struggling to improve quality: results from a systematic review of qualitative studies. BMJ Qual Saf 2019;28:74-84.

28 Solis Jet al. Structural vulnerability in the United States revealed in three waves of novel coronavirus disease (COVID-19). The American Journal of Tropical Medicine and Hygiene 2020:tpmd200391.

29 Zimmerman S, Sloane PD, Katz PR, et al. The need to include assisted living in responding to the COVID-19 pandemic. J Am Med Dir Assoc 2020;21:572-5.

30 Khan F, Driessen J. Bridging the telemedicine infrastructure gap: implications for long-term care in rural America. Public Policy Aging Report 2018;28:80-4.

31 Miller VJ. Investigating barriers to family visitation of nursing home residents: a systematic review. J Gerontol Soc Work 2019;62:261-78.

32 Stone PW, Chastain AM, Dorritie R, et al. The expansion of national healthcare safety network enrollment and reporting in nursing homes: lessons learned from a national qualitative study. Am J Infect Control 2019:47:615-22.
33 Hales Cet al. The care of older adults with extreme obesity in nursing homes: a collective case study. medRxiv 2019;19013326.

34 Jimenez-Sotomayor MR, Gomez-Moreno C, Soto-Perez-de-Celis E. Coronavirus, ageism, and twitter: an evaluation of tweets about older adults and COVID-19. J Am Geriatr Soc 2020;68:1661-5.

35 Han SD, Mosqueda L. Elder abuse in the COVID-19 era. J Am Geriatr Soc 2020;68:1386-7.

36 Fraser S, Lagacé M, Bongué B. Ageism and COVID-19: what does our society's response say about us? Age Ageing 2020;49:afaa097-695.

37 Comas-Herrera A, Fernandez J-L, Hancock R, et al. COVID-19: implications for the support of people with social care needs in England. J Aging Soc Policy 2020;32:365-72.

38 Gurwitz JH. COVID-19, post-acute care preparedness and nursing homes: flawed policy in the fog of war. J Am Geriatr Soc 2020;68:1124-5.

39 Ko M, Wagner L, Spetz J. Nursing home implementation of health information technology: review of the literature finds inadequate investment in preparation, infrastructure, and training. Inquiry 2018;55:004695801877890.

40 Bronfenbrenner $\mathrm{U}$. Toward an experimental ecology of human development. Am Psychol 1977;32:513-31.

41 Bronfenbrenner U. The ecology of human development: experiments by nature and by design. Cambridge, MA: Harvard University Press, 1979.

42 McLeroy KR, Bibeau D, Steckler A, et al. An ecological perspective on health promotion programs. Health Educ Q 1988;15:351-77.

43 Bronfenbrenner U, Morris A P. The bioecological model of human development, in Volume 1: theoretical models of human development. In: Handbook of child psychology, 2007.

44 Su Z, Wen J, McDonnell D, et al. Vaccines are not yet a silver bullet: the imperative of continued communication about the importance of COVID-19 safety measures. Brain Behav Immun Health 2021:12:100204.

45 Su Z, McDonnell D, Cheshmehzangi A, et al. With great hopes come great expectations: access and adoption issues associated with COVID-19 vaccines. JMIR Public Health Surveill 2021;7:e26111.

46 Su Z, McDonnell D, Wen J, et al. Young adults' preferences for influenza vaccination campaign messages: implications for COVID-19 vaccine intervention design and development. Brain Behav Immun Health 2021:14:100261.

$47 \mathrm{Su} Z$, McDonnell D, Ahmad J. The need for a disaster readiness mindset: a key lesson from the coronavirus disease 2019 (COVID-19) pandemic. Infect Control Hosp Epidemiol 2021:1-2.

48 Tollefson J. The race to curb the spread of COVID vaccine disinformation. Nature 2021. doi:10.1038/d41586-021-00997-x. [Epub ahead of print: 16 Apr 2021]

49 Su Z, McDonnell D, Wen J, et al. Mental health consequences of COVID-19 media coverage: the need for effective crisis communication practices. Global Health 2021;17:4.

50 Chiu C-J, Wu CH. Information and communications technology as a health promotion method for older adults in assisted-living facilities: three-arm group-randomized trial. JMIR Aging 2019;2:e12633.

51 Banbury A, Nancarrow S, Dart J, et al. Adding value to remote monitoring: Co-design of a health literacy intervention for older people with chronic disease delivered by telehealth - the telehealth literacy project. Patient Educ Couns 2020;103:597-606.

52 Su Z, Li X, McDonnell D, et al. Technology-Based interventions for cancer caregivers: concept analysis. JMIR Cancer 2021;7:e22140.

53 Ohannessian R, Duong TA, Odone A. Global telemedicine implementation and integration within health systems to fight the COVID-19 pandemic: a call to action. JMIR Public Health Surveill 2020;6:e18810.

54 Smith AC, Thomas E, Snoswell CL, et al. Telehealth for global emergencies: implications for coronavirus disease 2019 (COVID-19). $J$ Telemed Telecare 2020;26:309-13.

55 Wang J, Coleman DC, Kanter J, et al. Connecting smartphone and wearable fitness tracker data with a nationally used electronic health record system for diabetes education to facilitate behavioral goal monitoring in diabetes care: protocol for a pragmatic multi-site randomized trial. JMIR Res Protoc 2018;7:e10009.

56 Zhou X, Snoswell CL, Harding LE, et al. The role of telehealth in reducing the mental health burden from COVID-19. Telemed J E Health 2020;26:377-9.

57 Mette LA, Saldívar AMP, Poullard NE, et al. Reaching high-risk underserved individuals for cancer genetic counseling by videoteleconferencing. J Community Support Oncol 2016;14:162-8.

58 Hollander JE, Carr BG. Virtually perfect? Telemedicine for Covid-19. N Engl J Med Overseas Ed 2020;382:1679-81.

59 Wang J, Cai C, Padhye N, et al. A behavioral lifestyle intervention enhanced with multiple-behavior self-monitoring using mobile and 
connected tools for underserved individuals with type 2 diabetes and comorbid overweight or obesity: pilot comparative effectiveness trial. JMIR Mhealth Uhealth 2018;6:e92.

60 Keyworth C, Hart J, Armitage CJ, et al. What maximizes the effectiveness and implementation of technology-based interventions to support healthcare professional practice? A systematic literature review. BMC Med Inform Decis Mak 2018;18:93.

61 Ehn M, Johansson A-C, Revenäs Åsa. Technology-based motivation support for seniors' physical Activity-A qualitative study on seniors' and health care professionals' views. Int J Environ Res Public Health 2019;16. doi:10.3390/ijerph16132418. [Epub ahead of print: 0807 2019].

62 Bagot KL, Moloczij N, Barclay-Moss K, et al. Sustainable implementation of innovative, technology-based health care practices: a qualitative case study from stroke telemedicine. $J$ Telemed Telecare 2020;26:79-91.

63 Naylor MD, Hirschman KB, McCauley K. Meeting the transitional care needs of older adults with COVID-19. J Aging Soc Policy 2020;32:387-95.

64 Hado E, Friss Feinberg L. Amid the COVID-19 pandemic, meaningful communication between family caregivers and residents of long-term care facilities is imperative. J Aging Soc Policy 2020;32:410-5.

65 Prieto-Flores M-E, Forjaz MJ, Fernandez-Mayoralas G, et al. Factors associated with loneliness of noninstitutionalized and institutionalized older adults. J Aging Health 2011;23:177-94.

66 Mahmood S, Hasan K, Colder Carras M, et al. Global preparedness against COVID-19: we must leverage the power of digital health. JMIR Public Health Surveill 2020;6:e18980.

67 Banskota S, Healy M, Goldberg EM. 15 smartphone apps for older adults to use while in isolation during the COVID-19 pandemic. West J Emerg Med 2020;21:514-25.

68 Moher D, Shamseer L, Clarke M, et al. Preferred reporting items for systematic review and meta-analysis protocols (PRISMA-P) 2015 statement. Syst Rev 2015;4:1.

69 Stewart L, Moher D, Shekelle P. Why prospective registration of systematic reviews makes sense. Syst Rev 2012;1:7.

70 Chang SM, Slutsky J. Debunking myths of protocol registration. Syst Rev 2012;1:4.

71 Xu C, Cheng L-L, Liu Y, et al. Protocol registration or development may benefit the design, conduct and reporting of dose-response meta-analysis: empirical evidence from a literature survey. BMC Med Res Methodol 2019;19:78.

72 Dos Santos MBF, Agostini BA, Bassani R, et al. Protocol registration improves reporting quality of systematic reviews in dentistry. BMC Med Res Methodol 2020;20:57.
73 Shokraneh F. Reproducibility and replicability of systematic reviews. World J Metaanal 2019;7:66-76.

74 Ramstrand N, Fatone S, Dillon MP, et al. Promoting quality and transparency in clinical research. Prosthet Orthot Int 2019;43:474-7.

75 Higgins JPT, Altman DG, Gøtzsche PC, et al. The Cochrane collaboration's tool for assessing risk of bias in randomised trials. BMJ 2011;343:d5928.

76 Thomas KS, Dosa D, Gozalo PL, et al. A methodology to identify a cohort of Medicare beneficiaries residing in large assisted living facilities using administrative data. Med Care 2018;56:e10-15.

77 Toumazou C, Hughes JB, Battersby NC. Switched currents: an analogue technique for digital technology. London, United Kingdom: Peter Peregrinus Ltd. On behalf of the Institution of Engineering and Technology, 1993.

78 Higgins JPet al. Cochrane handbook for systematic reviews of interventions. John Wiley \& Sons, 2019

79 Resnik DB. What is ethics in research \& why is it important? 2020. Available: https://www.niehs.nih.gov/research/resources/bioethics/ whatis/index.cfm [Accessed 01 Oct 2021].

80 Goodman-Casanova JM, Dura-Perez E, Guzman-Parra J, et al. Telehealth home support during COVID-19 confinement for community-dwelling older adults with mild cognitive impairment or mild dementia: survey study. J Med Internet Res 2020;22:e19434

81 Gao Z, Lee JE, McDonough DJ, et al. Virtual reality exercise as a coping strategy for health and wellness promotion in older adults during the COVID-19 pandemic. J Clin Med 2020;9. doi:10.3390/ jcm9061986. [Epub ahead of print: 2506 2020].

82 Su Z, Liang B, Shi F, et al. Deep learning-based facial image analysis in medical research: a systematic review protocol. BMJ Open 2021;11:e047549.

83 Schneider JE, Cooper J, Scheibling C, et al. Economic evaluation of passive monitoring technology for seniors. Aging Clin Exp Res 2020;32:1375-82.

84 Sapci AH, Sapci HA. Innovative assisted living tools, remote monitoring technologies, artificial intelligence-driven solutions, and robotic systems for aging societies: systematic review. JMIR Aging 2019;2:e15429.

85 Su Z, Su Z. Rigorous policy-making amid COVID-19 and beyond: literature review and critical insights. Int J Environ Res Public Health 2021;18:12447. doi:10.3390/ijerph182312447

86 Su Z, McDonnell D, Liang B, et al. Technology-Based health solutions for cancer caregivers to better shoulder the impact of COVID-19: a systematic review protocol. Syst Rev 2021;10:43.

87 Su Z, McDonnell D, Bentley BL, et al. Addressing Biodisaster X threats with artificial intelligence and 6G technologies: literature review and critical insights. J Med Internet Res 2021;23:e26109. 